\title{
Burden, Coping, Physical Symptoms and Psychological Morbidity in Caregivers of Functionally Dependent Family Members ${ }^{1}$
}

\author{
Ana Catarina Guedes ${ }^{2}$ \\ Maria da Graça Pereira ${ }^{3}$
}

\begin{abstract}
Objectives: this study assessed burden, coping, physical symptoms and psychological morbidity in caregivers of functionally dependent family members. Methods: fifty family caregivers completed self-reported measures of burden, physical symptoms, psychological morbidity and coping strategies. Results: there was a significant negative correlation between coping strategies and the different clinical variables, as well as a significant positive correlation between coping strategies and duration of care. It appears that the stronger bond between caregiver and family member leads to a poorer use of adaptive coping strategies. It also appears that the deterioration of the relationship between them and the lower perceived self-efficacy are more prominent in caregivers of family members with cognitive impairment, indicating that caregivers with family members without cognitive impairment face fewer difficulties. Conclusion: these results emphasize the need for interventions to include coping strategies, since they are important in reducing caregivers' burden, psychological morbidity and physical symptoms.
\end{abstract}

Descriptors: Caregivers; Adaptation, Psychological; Home Nursing; Family Relations.

\footnotetext{
${ }^{1}$ Paper extracted from master's thesis "Sobrecarga, Sintomatologia Física, Morbilidade Psicológica e Coping em Cuidadores de Familiares com Apoio de Enfermagem Domiciliário" presented to Escola de Psicologia, Universidade do Minho, Braga, Portugal. ${ }^{2} \mathrm{MSc}$.

${ }^{3} \mathrm{PhD}$, Associate Professor, Escola de Psicologia, Universidade do Minho, Braga, Portugal.
} 


\section{Introduction}

The ageing of the population and the emergence of numerous chronic diseases have contributed to the increased number of individuals with disabilities susceptible to causing functional dependence and impairments $^{(1)}$ that require medium to long term support at the family, social and health levels ${ }^{(2)}$. The family is required to restructure itself in order to provide care and many adjustments occur over time in the caregiver's lifestyle(3). The resulting burden of care is positively correlated with the severity of the dependency ${ }^{(4)}$, the amount of time spent in care ${ }^{(4)}$, the appearance of physical symptoms(5), the deterioration of caregivers' psychological well-being(6), the caregiver gender (female caregivers are more prone to suffer from burden) ${ }^{(4)}$, and the old age of the caregiver(7). Caregivers may also develop higher levels of psychological morbidity(8) and physical symptoms ${ }^{(9)}$.

The relationship between stressful events, faced by caregivers, and the physical and psychological symptoms is mediated by coping processes ${ }^{(10)}$, whereby self-efficacy and competency perceptions (coping strategies) are able to mediate the relationship between the stressful event and the distress experienced by the caregiver, leading to better health ${ }^{(11)}$.

However, often, the caregiving situation comes unexpectedly and caregivers may not be prepared for the required responsibility and, as a result, self-efficacy and competency perceptions may not be present. Therefore, it is of vital importance that caregivers be prepared through educational strategies on how to care. Education is necessary for the acquisition of knowledge and skills necessary to adapt to the caregiving situation ${ }^{(3)}$. Thereby, nurses may inform caregivers about the disease, strengthen self-care and minimize their burden. Care involves the patient and the caregiver, who becomes an important element in the nursing team ${ }^{(12)}$.

Despite the importance of the caregiver, professional practice needs more research, in order to identify caregivers' needs and strengths and develop and implement good health education programs, targeted at caregivers. The present study focused on the relationships among burden, physical symptoms, coping and psychological morbidity in caregivers and on the differences in these psychological variables, taking in consideration the type of caregiver (spouse/ offspring caregivers versus other caregivers), the presence /absence of the family member's cognitive impairment (besides functional dependency) and the caregiver's gender.

\section{Methods}

\section{Participants}

The sample comprised 50 informal caregivers of a family member with functional dependence assessed by the Barthel Index; aged 18 years or older and receiving preventive and/or curative home nursing care from two health care centres in the North of Portugal.

\section{Instruments}

The Barthel Index (IB) ${ }^{(13)}$, composed of 10 basic activities of daily living. A lower score is associated with greater dependence. Cut-off points for dependence are: $<20$ points (total); $20-35$ points (severe); 40-55 points (moderate); 60-90 points (slight); 90-100 points (independence) $^{(14)}$. Cronbach's alpha for the Barthel Index, in the present study, was .89.

Mini-Mental State Examination (MMSE) ${ }^{(15)}$ includes 11 items, grouped in five categories (orientation; retention; attention and calculation; evocation; language). The total score ranges from 0 to 30 . Cognitive impairment is defined when the total score is equal or less than 15 in illiterates; equal or less than 22 in caregivers with 1 to 11 years of education; and equal or less than 27 in caregivers with more than 11 years of education(16). Cronbach's alpha, in this sample, was .91.

Burden Interview Scale $(\mathrm{ZBI})^{(17)}$ includes 22 items, using a five-point scale, that assess burden in caregivers, divided in four factors: "impact of care", "interpersonal relationship", "expectations with caring" and "self-efficacy perception"(14). High scores indicate higher levels of burden. In the current study, Cronbach's alphas for "impact of care", "interpersonal relationship", "expectations with caring", "self-efficacy perception" and total score were $.86, .75, .23, .88$ and .87 , respectively. Health Symptoms Checklist (HSC) ${ }^{(18)}$ was used to measure the level and frequency at which a specific symptom affected the caregiver in the month prior to the assessment. High scores indicate more physical symptoms. Cronbach's alpha in the present sample was .89 .

Depression Anxiety Stress Scales ${ }^{(19)}$ includes 21 items grouped in three scales: anxiety, depression and stress. Higher scores indicate high levels of anxiety, depression and stress respectively. In the current study, Cronbach's alphas for anxiety, depression and stress were $.80, .83$ and .86 , respectively.

Carer's Assessment of Managing Index (CAMI) (20) includes 38 items, assessing coping strategies. A higher 
score indicates the use of more effective coping strategies. CAMI includes three subscales: "dealing with events/ problem solving"; "alternative perceptions of the situation"; "dealing with symptoms of stress"(14). In the current study, Cronbach's alphas were $.84, .80, .37$, respectively, for the three subscales, and .90 for the total subscale.

\section{Procedure}

After approval by the executive directors of the two health care centres, caregivers who complied with the inclusion criteria were selected and invited to participate in the study. All caregivers were informed about the research objectives, confidentiality, and the right to discontinue their participation. Data collection took place during nursing home visits by the researcher, only after an informed consent, signed by the participants.

\section{Data Analyses}

Spearman correlations were used to analyse the relationships among psychological variables and MannWhitney tests were employed to assess differences in psychological variables according to: type of caregiver; presence versus absence of family member's cognitive impairment and caregiver's gender.

\section{Results}

Most caregivers were female $(78 \%)$. The mean age was 56 years old, with an average education of 5.46 years, mostly retired or unemployed (68\%). Seventytwo percent were married or cohabitating with the family member and provided care for over three years (52\%). Sixty-six percent of family members receiving care were totally or severely dependent and $64 \%$ presented cognitive impairment.

\section{Relationships Among Coping Strategies, Burden, Physical Symptoms, Psychological Morbidity and Duration of Caregiving}

Significant negative correlations between effective coping strategies, anxiety and interpersonal relationship (burden) were found, as well as a positive relationship between coping strategies and duration of caregiving (Table 1 ).

There were significant negative correlations between alternative perceptions of the situation (coping), depression and stress. Significant negative correlations were found between anxiety and the dimensions of coping "dealing with events" and "alternative perceptions of the situation".

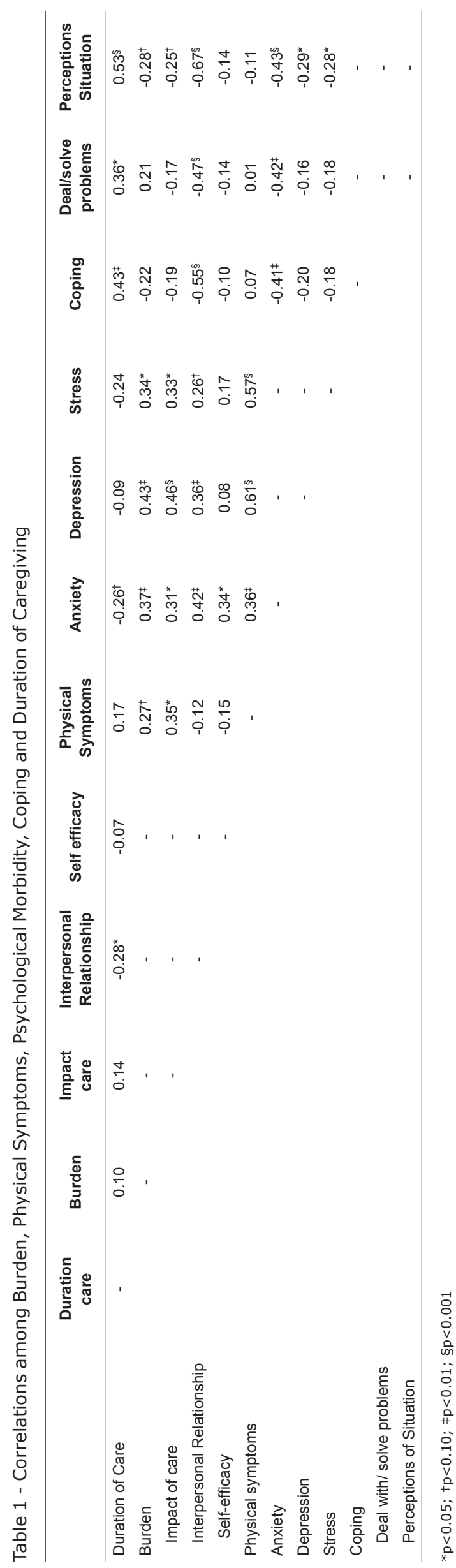


Differences in Burden, Physical Symptoms, Psychological Morbidity and Coping Between Spouse/ Offspring Caregivers versus Other Caregivers

There were significant differences between spouses/ offspring caregivers compared to other caregivers (in laws, nephews, brothers), with the latter reporting more use of coping strategies, especially "dealing with the situation or solving the problem" and "alternative perceptions of the situation" (Table 2).

Table 2 - Differences in Burden, Physical Symptoms, Psychological Morbidity levels and Coping according to Relationship with Family Member

\begin{tabular}{|c|c|c|c|}
\hline & \multicolumn{2}{|c|}{ Mean Rank } & \multirow[b]{2}{*}{$\mathbf{Z}$} \\
\hline & $\begin{array}{c}\text { Spouses/ } \\
\text { Offspring } \\
\quad(n=37)\end{array}$ & $\begin{array}{l}\text { Others } \\
(n=13)\end{array}$ & \\
\hline Burden & 26.70 & 22.80 & -0.99 \\
\hline Impact of care & 27.45 & 19.96 & -1.60 \\
\hline Interpersonal Relationship & 26.95 & 21.38 & -1.19 \\
\hline Self-Efficacy & 24.05 & 29.62 & -1.28 \\
\hline Physical symptoms & 24.88 & 27.27 & -0.51 \\
\hline Anxiety & 26.42 & 22.88 & -0.76 \\
\hline Depression & 26.23 & 23.42 & -0.60 \\
\hline Stress & 25.54 & 25.38 & -0.03 \\
\hline Coping & 23.01 & 32.58 & $-2.04^{*}$ \\
\hline Dealing with the situation & 22.88 & 32.96 & $-2.15^{*}$ \\
\hline $\begin{array}{l}\text { Alternative perceptions of the } \\
\text { situation }\end{array}$ & 22.91 & 32.88 & $-2.13^{*}$ \\
\hline
\end{tabular}

Differences in Burden, Physical Symptoms, Psychological Morbidity and Coping According to Family Member's Cognitive Impairment

Caregivers of family members with cognitive impairment report higher burden at the level of interpersonal relationship and self-efficacy perception. On the other hand, caregivers of family members without cognitive impairment use more coping strategies, which allow them to have a different perspective of the situation (Table 3 ).

There were no significant differences in burden, physical symptoms, psychological morbidity and coping according to caregiver gender. However, women showed more anxiety than men.
Table 3 - Differences in Burden, Physical Symptoms, Psychological Morbidity and Coping according to Family's Member Cognitive Impairment

\begin{tabular}{lccc}
\cline { 2 - 3 } & \multicolumn{2}{c}{ Mean Rank } & \\
\cline { 2 - 3 } & $\begin{array}{c}\text { Without } \\
\text { cognitive } \\
\text { impairment }\end{array}$ & $\begin{array}{c}\text { With } \\
\text { cognitive } \\
\text { impairment }\end{array}$ & Z \\
& (n=18) & (n=32) & \\
\hline Burden & 23.69 & 26.52 & -0.66 \\
Impact of care & 25.17 & 25.69 & -0.12 \\
Interpersonal Relationship & 20.14 & 28.52 & $-1.96^{*}$ \\
Self-Efficacy & 18.61 & 29.38 & $-2.71^{\dagger}$ \\
Physical symptoms & 28.75 & 23.67 & -1.18 \\
Anxiety & 22.86 & 26.98 & -0.97 \\
Depression & 22.75 & 27.05 & -1.01 \\
Stress & 26.75 & 24.80 & -0.46 \\
Coping & 28.50 & 23.81 & -1.09 \\
$\quad$ Dealing with the situation & 28.11 & 24.03 & -0.95 \\
Alternative perceptions of the & 30.28 & 22.81 & $-1.74^{\ddagger}$ \\
situation & & & \\
\hline
\end{tabular}

$* p<0.05 ;+p<0.01 ; \neq p<0.10$

\section{Discussion}

Results showed that longer duration of care was associated with lower levels of burden and psychological morbidity, and the use of coping strategies; higher levels of anxiety and burden were associated with less use of effective coping strategies; spouse/offspring caregivers showed less use of effective coping strategies; caregivers of cognitive impaired family members reported less use of coping strategies and higher deterioration in their relationship with the family member and finally, female caregivers reported higher levels of anxiety (marginal differences).

The current study results did not provide support for previous findings showing that female caregivers were more likely to suffer from psychological morbidity(21). However, a trend in that direction was found. This result may be due to the size of the sample in this study. Therefore, future studies should use bigger samples.

In this study, the coping strategies were positively correlated with caregiving duration and negatively with psychological morbidity and burden. In fact, caregivers acquire more competencies and coping strategies (e.g. "alternative perceptions of the situation", "deal/ 
solve the problems") as time goes by and, therefore, it comes as no surprise that burden and morbidity decrease $^{(14)}$. The less use of effective coping strategies (e.g. "alternative perceptions of the situation", "deal with/solve the problems") was associated with higher levels of anxiety, depression, stress and burden. This result is in accordance with the literature, indicating that anxious caregivers try to minimize or avoid stressful situations ${ }^{(22)}$.

The use of coping strategies "deal with/ solve the problem" and "alternative perception of the situation", by "other" caregivers who are not so emotionally connected with the family member was associated with fewer burdens, physical symptoms and psychological morbidity. This result shows the importance of the strong emotional bond between the family member and the spouse/offspring. In fact, when that occurs, the caregiver makes poorer use of these coping strategies $^{(23)}$.

The results also support previous findings, indicating that caregivers of family members without cognitive impairment use more adaptive coping strategies (e.g. "alternative perceptions of the situation"), reflecting fewer difficulties in dealing with stressful situations ${ }^{(14)}$.

Results also showed that caregivers reported further deterioration in their relationship with family members when the latter present cognitive impairment. In fact, reduced intimacy, poor communication skills(24), less shared activities and reduced opportunities to explore the relationship(25) are strong predictors of burden regarding interpersonal relationships.

The interpretation of the results, in the present study, should take into account the study's limitations, especially the small number of caregivers; the fact that the sample included only caregivers from the North of Portugal; the low alpha of the dimension "expectations with care" in the Burden Interview Scale and the dimension "deal with the symptoms of stress" from the Carers' Assessment of Managing Index that prevented their use.

\section{Conclusion}

The present findings show that effective coping strategies were negatively correlated with psychological morbidity, physical symptoms and burden. The present results stress the importance of coping strategies, as protective means of caregivers' physical and psychological health. Therefore, interventions should emphasize skills and coping strategies in order to minimize caregivers' burden, enabling them to provide better care and, as a result, indirectly decreasing family members' institutionalization.

\section{References}

1. Pearlin LI, Aneshensel CS. Caregiving: The Unexpected Career. Social Justice Res. 1994;7(4):373-90.

2. Lage I. Cuidados familiares a idosos. In: Paúl C, Fonseca AM. Envelhecer em Portugal. Lisboa: Climepsi Editores; 2005. p. 203-29.

3. Nogueira PC, Rabeh SAN, Caliri MHL, Dantas RAS, Haas VJ. Burden of care and its impact on health related quality of life of caregivers of individuals with spinal cord injury. Rev. Latino-Am. Enfermagem. 2012;20(6):1048-56.

4. Garcés J, Carretero S, Ródenas F, Sanjosé V. Variables related to the informal caregivers' burden of dependent sénior citizens in Spain. Arch Gerontol Geriatrics. 2009;48:372-9.

5. Coe NB, Houtven $\mathrm{CH}$. Caring for mom and neglecting yourself? The health effects of caring for an elderly parent. Health Economics. 2009;18: 991-1010.

6. Pot AM, Deeg JH, Dyck RV. Psychological wellbeing of informal caregivers of elderly people with dementia: changes over time. Aging Mental Health. 1997;1(3):261-8.

7. Rinaldi $P$, Spazzafumo $L$, Mastriforti $R$, Mattioli $M$, Polidori MC, Cherubini A, et al. Predictors of high level of burden and distress in caregivers of demented patients: results of an Italian multicenter study. Int J Geriatric Psychiatry. 2005;20:168-74.

8. Covinsky KE, Newcomer R, Fox P, Wood J, Sands $L$, Dane $K$, et al. Patient and Caregiver Characteristics Associated with Depression in Caregivers of Patients with Dementia. J Gen Intern Medicine. 2003;18:1006-14.

9. Larrañaga I, Martín U, Bacigalupe A, Begiristáin JM, Valderrama MJ, Arregi B. Impacto del cuidado informal en la salud y la calidad de vida de las personas cuidadoras: análisis de las desigualdades de género. Gaceta Sanit. 2008;22(5):443-50.

10. Folkman S, Lazarus RS, Gruen RJ, Delongis A. Appraisal, Coping, Health Status, and Psychological Symptoms. J Person Soc Psychol. 1986;50(3):571-9.

11. Salin S, Kaunonen M, Astedt-Kurki P. Informal carers of older family members: how they manage and what support they receive from respite care. J Clin Nurs. 2009;18:492-501.

12. Souza LM, Wegner W, Gorini MIPC. Health education: a strategy of care for the lay caregiver. Rev. Latino-Am. Enfermagem. 2007;15(2):337-43. 
13. Mahoney FI, Barthel DW. Functional Evaluation: The Barthel Index. Maryland State Med J. 1965;14:56-61.

14. Sequeira C. Cuidar de idosos dependentes. Diagnósticos e intervenções. Coimbra: Editora Quarteto; 2007.

15. Folstein MF, Folstein SE. Mini-Mental state. A practical method for grading the cognitive state of patients for the clinician. J Psychiatr Res. 1975;12:189-98.

16. Guerreiro M, Silva AP, Botelho A, Leitão O, CastroCaldas A, Garcia C. Adaptação à população portuguesa da tradução do Mini Mental State Examination (MMSE). Coimbra: Reunião da Primavera da Sociedade Portuguesa de Neurologia; 1994.

17. Zarit SH, Zarit JM. The memory and behaviour problems checklist - and the burden interview. United States of America (USA): Pennsylvania State University; 1983.

18. Proctor SP, Heeren T, White RF, Wolfe J, Borgos MS, Davis JD, et al. Health status of Persian Gulf War veterans: self-reported symptoms, environmental exposures and the effect of stress. Int J Epidemiol. 1998;27:1000-10.

19. Lovibond PF, Lovibond SH. The structure of negative emotional states: comparison of the Depression Anxiety Stress Scales (DASS) with the Beck Depression and Anxiety Inventories. Behav Res Therapy. 1995;33(3):335-43.

20. Nolan M, Grant G, Keady J. Understanding family care: a multidimensional model for caring and coping. Buckingham: Open University Press; 1996.

21. Idstad M, Ask H, Tambs K. Mental disorder and caregiver burden in spouses: the Nord-Trøndelag health study. BMC Public Health. 2010;10(516):1-7.

22. Di Mattei VE, Pruna A, Novel L, Marcone A, Cappa SF, Sarno $L$. The burden of distress in caregivers of elderly demented patients and its relationship with coping strategies. Neurol Sci. 2008; 29:383-9.

23. Barbosa A, Figueiredo D, Sousa L, Demain S. Coping with the caregiving role: Differences between primary and secondary caregivers of dependent elderly people. Aging Mental Health. 2011;15(4):490-9.

24. Campbell P, Wright J, Oyebode J, Job D, Crome $\mathrm{P}$, Bentham $\mathrm{P}$, et al. Determinants of burden in those who care for someone with dementia. Int J Geriatric Psychiatry. 2008;23:1078-85.

25. Atkins L, Brown RG, Leigh PN, Goldstein LH. Marital relationships in amyotrophic lateral sclerosis. Amyotroph Lateral Scler. 2010;11:344-50. 